\title{
Quality improvement teaching at medical school: a student perspective
}

This article was published in the following Dove Press journal:

Advances in Medical Education and Practice

18 March 2016

Number of times this article has been viewed

Pooja Nair

Ishani Barai

Sunila Prasad

Karishma Gadhvi

Department of Medicine, Imperial College School of Medicine, Imperial College London, London, UK
Correspondence: Pooja Nair Department of Medicine, Sir Alexander Fleming Building, Exhibition Road, South Kensington Campus, Imperial College, London SW7 2AZ, UK Email pooja.nair I @@imperial.ac.uk

\begin{abstract}
Guidelines in the UK require all doctors to actively take part in quality improvement. To ease future doctors into the process, formal quality improvement teaching can be delivered during medical school.

Keywords: quality improvement, medical school, patient safety, patient satisfaction, medical student, clinical audit
\end{abstract}

\section{Introduction}

The National Health Service is defined by its ability to deliver high standards of care and has a long-standing commitment to patient safety. To maintain this ethos, the core values of quality improvement must be instilled in future doctors at medical school. The General Medical Council supports this principle with expectations that "all doctors take part in systems of quality assurance and quality improvement that will form part of their assessment in the upcoming appraisal and revalidation process."

\section{Quality improvement in the medical student curriculum}

Gould et $\mathrm{al}^{2}$ highlighted that medical students represent an "under-utilized resource," with the potential to considerably improve patient care through student-led clinical quality improvement projects. A study based in Dartmouth Medical School has corroborated the benefits of student involvement in clinical projects, such as an improved awareness of clinical issues and ability to provide novel approaches. ${ }^{3}$ The success of the Institute for Healthcare Improvement, an international forum that enables motivated medical students to learn the key principles of quality improvement, suggests growing interest in this area. ${ }^{4}$ However, despite the inclusion of quality improvement into the curricula of many US and UK medical schools, it has been reported that there are significant differences in the delivery of such teaching at the undergraduate level, and therefore medical students qualify with varying degrees of exposure to quality improvement. ${ }^{5}$ A survey by Teigland et $\mathrm{al}^{6}$ highlighted that over $50 \%$ of medical students reported inadequate exposure to quality improvement at medical school despite recognizing its importance for their future careers.

In view of these findings, how can medical schools successfully integrate this professional requirement into a high-yield learning experience for students?

As medical students at Imperial College London, we have benefited from structured quality improvement teaching integrated into our first clinical year. This course com-

submit your manuscript | www.dovepress.con 
prised of introductory lectures on the fundamental principles of quality improvement, followed by a formally assessed group assignment spanning 10 weeks. In small groups of three to five students, we recognized areas for improvement in our respective clinical environments and formulated various quality improvement strategies. Projects addressed and critically evaluated the impact of a wide range of issues, including patient satisfaction, patient safety, and efficiency of the workplace environment. Several projects were implemented under the guidance of physicians and other health care staff members, and results were evaluated after one cycle of change. Findings were delivered by oral and poster presentations with specific feedback provided by a panel of senior clinicians, health care managers, and peers. Feedback encompassed comments about the project design, implementation, analysis of results, and discussion, as well as suggestions for improvement. This assignment incorporated some of the key requirements for engaging students in medical leadership, as suggested by the Academy of Royal Medical Colleges. ${ }^{7}$ The most beneficial aspect of this integrated module was the opportunity provided to actively participate in finding solutions for real problems in the clinical setting, of which some ideas have been formally implemented by hospitals. Our engagement with this initiative will undoubtedly encourage further involvement and contribution in service improvement, regardless of our respective career paths.

Taking into consideration the dense medical student curriculum, introduction of additional teaching on quality improvement may be met with resistance. Further work including prospective studies and statistical evaluation may be useful in determining the most effective method in which quality improvement teaching can be delivered to medical students.

\section{Conclusion}

Quality improvement is a continuous learning process with timely assessment and development and is a concept that has been endorsed in medical education by regulating authorities in recent years. Integration of formal quality improvement teaching into every medical school curriculum will provide a unique opportunity to learn by doing and ensure all future doctors are equipped with the essential skill set to identify areas for improvement in our health care system.

\section{Disclosure}

The authors report no conflicts of interest in this work.

\section{References}

1. The Good Medical Practice framework for practice and appraisal. General Medical Council; 2013. Available from: http://www.gmc-uk.org/static/ documents/content/GMC_Revalidation_A4_Guidance_GMP_Framework_04.pdf. Accessed November 24, 2015.

2. Gould BE, Grey MR, Huntington CG, et al. Improving patient care outcomes by teaching quality improvement to medical students in community-based practices. Acad Med. 2002;77(10):1011-1018.

3. Weeks WB, Robinson JL, Brooks WB, Batalden PB. Using early clinical experiences to integrate quality-improvement learning into medical education. Acad Med. 2000;75(1):81-84.

4. IHI.org [homepage on the Internet]. Institute for Healthcare Improvement; c2015. Available from: http://www.ihi.org/Pages/default.aspx. Accessed November 24, 2015.

5. Nie Y, Li L, Duan Y, et al. Patient safety education for undergraduate medical students: a systematic review. BMC Med Educ. 2011;11:33.

6. Teigland CL, Blasiak RC, Wilson LA, Hines RE, Meyerhoff KL, Viera AJ. Patient safety and quality improvement education: a cross-sectional study of medical students' preferences and attitudes. BMC Med Educ. 2013;13:16.

7. Guidance for Undergraduate Medical Education: Integrating the Medical Leadership Competency Framework. Academy of Royal Medical Colleges; 2010. Available from: http://www.aomrc.org.uk/doc_view/227undergraduate-guidance-for-medical-education-integrating-the-mlcf. Accessed December 10, 2015.
Advances in Medical Education and Practice

\section{Publish your work in this journal}

Advances in Medical Education and Practice is an international, peerreviewed, open access journal that aims to present and publish research on Medical Education covering medical, dental, nursing and allied health care professional education. The journal covers undergraduate education, postgraduate training and continuing medical education

\section{Dovepress}

including emerging trends and innovative models linking education, research, and health care services. The manuscript management system is completely online and includes a very quick and fair peer-review system. Visit http://www.dovepress.com/testimonials.php to read real quotes from published authors. 